\title{
To switch or not to switch? - Understanding German consumers' willingness to pay for green electricity tariff attributes
}

\section{Michael Danne ( $\nabla$ michael.danne@agr.uni-goettingen.de)}

Departement of Agriculture and Rural Developement, Farm Management Group, University of Göttingen https://orcid.org/0000-0003-0468-5054

\section{Saramena Sauthoff}

Georg-August-Universitat Gottingen

\section{Oliver Musshoff}

Departement of Agriculture and Rural Developement, University of Goettingen

\section{Original article}

Keywords: Energy transition, green energy, tariff switch, discrete choice experiment, generalized multinomial logit model, WTP space

Posted Date: April 20th, 2020

DOl: https://doi.org/10.21203/rs.3.rs-20848/v1

License: (c) (i) This work is licensed under a Creative Commons Attribution 4.0 International License. Read Full License

Version of Record: A version of this preprint was published at Energy, Sustainability and Society on May 19th, 2021. See the published version at https://doi.org/10.1186/s13705-021-00291-8. 


\section{Abstract \\ Background}

In order to achieve an environmentally friendly and sustainable energy supply, it is necessary that this goal is supported by society. In different countries worldwide it has been shown that one way consumers want to support the energy transition is by purchasing green electricity. However, few people make the leap from their intention to a buying decision. This study explores parameters that influence whether German consumers decide to switch to a green electricity tariff.

\section{Methods}

We conducted a quota-representative online survey including a discrete choice experiment with 371 private households in Germany in 2016. For the econometric analysis, a generalized multinomial logit model in willingness to pay space was employed, enabling the estimation of WTP values to be as realistic as possible.

\section{Results}

The results show that consumers' decision regarding whether or not to make the switch to green energy is mainly influenced by the source of green energy, whether a person can outsource the switching process, and a person's attitude towards the renewable energy sources levy that currently exists in Germany.

\section{Conclusions}

As our findings indicate politics should focus on supporting wind and solar energy as German consumers prefer this sources over biogas. As suggested by our results, the EEG levy is a reason why consumers have lower WTP for a switch to a green tariff. Therefore a switching bonus with a specifically "framed" bonus in the amount of the current EEG levy could be a promising strategy for the increase of green energy tariff acceptance. Furthermore, attention should be given to psychological and behavioral aspects, as our results indicate that these factors influence the consumer's choice for a green electricity tariff.

\section{Introduction}

It is commonly agreed that the climate is changing due to anthropogenic greenhouse gas emissions. Thus, in the last three decades, the goal of bringing a halt to climate change emerged. Increasing the share of renewables in energy consumption is a key component of many countries' strategies to achieve climate protection $[1,2,3]$. The European Union (EU), for example, aspires to take a leading role and has set ambitious targets in international climate protection $[4,5,6]$, such as that by 2030 , at least $27 \%$ of its energy should come from renewables [7]. Germany, as the greatest greenhouse gas emitter in Europe and 
a country with even more ambitious climate protection goals than those of the EU, serves as an example in this study $[8,9]$. As a member of the EU, the German government laid the foundation for its energy transition process with the Renewable Energy Sources Act (EEG) in 2000 [10]. By 2015, renewable energy sources (RES) already accounted for more than $30 \%$ of the gross electricity consumption in Germany [11]. However, the amendment of the law in 2014 aims to continuously and cost-efficiently increase the share of electricity generated from RES to at least $40 \%$ by 2025 [12].

In addition to political interests that are involved in the promotion of renewable energies, there is also an increasing demand among consumers. Numerous studies show that consumers have an additional willingness to pay (WTP) for electricity from RES, the so-called green electricity [13-21]. A meta-analysis found that German consumers have one of the highest WTPs for green electricity compared to consumers of other countries [21].

However, although consumers claim to have a willingness to support the development of renewable energies by purchasing green electricity, the number of actual adoptions of green energy tariffs differs greatly from the intended willingness to change $[22,23]$. Thus, it can be assumed that there are obstacles that hinder consumers in the transition to a green electricity tariff, such as high transaction costs, insufficient financial incentives (e.g. no switching bonus payments), and a lack of information on the potential provider or tariff $[16,24,25,26]$.

Against this background, the research challenge of this paper is to give new insights in consumers' willingness to switch to green electricity tariffs in order to better understand the gap between a supportive consumer intention to buy green energy and a low actual tariff adoption rate. It is therefore important to analyze consumers' preferences for green electricity products in order to draw conclusions about their future development potential. A relevant study in this context was conducted by Kaenzig et al. [16], who used a quota-representative dataset from 2009 to investigate whether German consumers have a WTP for an upgrade from the default electricity mix to a more environmentally friendly electricity mix. To address their research question, they employed a stated preferences survey including a discrete choice experiment (DCE). However, consumer preferences for green electricity may have changed since 2009, as there were several events that may have had an influence, such as Fukushima's nuclear accident in 2011 [27] after which the German Government decided to abandon nuclear power and expand renewable energies even more. Furthermore, it can be observed that the strong expansion of some RES, such as increasing biogas production and installation of wind power plants, has resulted in some negative response, especially from consumers [28-31]. It is therefore of interest for the present study to measure consumer preferences for several single RES, as we assume that these are currently more likely to be valued by consumers than a mix of different (renewable) energy sources, as was investigated by Burkhalter et al. [32], Groesche and Schroeder [33] and Kaenzig et al. [16]. Furthermore, this study is the first to use an experimental design which is based on existing comparison portals. This is advantageous since consumers use online comparison portals as their main information resource to gain information regarding different electricity tariffs [34]. 
In this research, a DCE was applied, which allows conclusions to be drawn about future behavior from the results of hypothetical scenarios [35]. In designing our analysis, we referred to Fiebig et al. [36], who developed an advanced framework, the so-called generalized multinomial logit (GMNL) model, which considers preference and scale heterogeneity. The latter is particularly relevant, as each consumer interprets and responds to decision situations differently in such choice experiments. Thus, another novelty of this paper is that we transferred the GMNL model to the field of preference measurement in the green energy sector. In order to derive WTP values for the attributes of the DCE that are as realistic as possible, the model was specified in WTP space [37]. Additionally, a further important characteristic of our study is that we allowed for correlations between the random WTP coefficients of the tariff attributes. These have often not been regarded in previous WTP space studies (with the known exceptions of Balogh et al., [38]; Balcombe et al., [39, 40]. By taking these correlations into account, estimations of consumer preferences for switching to a green electricity tariff are potentially more realistic.

The gap between the WTP for green electricity tariffs and actual adoption poses a problem for both political actors and electricity marketers. However, to enable the best possible energy transition, active participation of consumers in purchasing green electricity is indispensable in the long term. Therefore, this study provides insights for policy makers and electricity marketers that help to understand what motivates (discourages) consumers to switch to green electricity tariffs.

\section{Theoretical Background And Development Of Hypotheses}

To increase the willingness to switch to green electricity and thus to make a long-term contribution to the energy transition, it is necessary to be aware of the drivers and obstacles that are decisive for consumers in choosing such a tariff. In the following, influential factors in the decision-making process of private electricity consumers are considered and hypotheses are developed.

\subsection{Different preferences regarding various RES}

The source of renewable electricity can influence the consumer's preference when choosing a green electricity tariff. In this context, different studies indicate that most consumers are generally willing to pay extra for green electricity, but the amount of this additional cost varies for different RES [16, 20, 41-45]. Ek [43] found that Swedish households generally favor the production of wind energy. A study by Borchers et al. [41] revealed that, from the US consumer perspective, the benefits of solar power exceed the benefits of wind energy, followed biomass and biogas energy, which were valued similarly and in third place after solar and wind energy. Cicia et al. [42] found a group of Italian respondents who prefer wind and solar energy, but reject energy from biomass. Similarly, Gracia et al. [44] revealed a WTP for solar and regionally produced energy by Spanish consumers, whereas the proposition of wind energy and energy from biomass leads to a request for discount. Burkhalter et al. [32] showed for the German electricity market that an RES electricity mix is more preferred by the consumer than electricity from only one RES. In a more recent study, Kaenzig et al. [16], however, found that the German consumer has a preference order, in which pure wind energy is valued above a green energy mix, which in turn is valued above a mix 
of renewable energies, coal and nuclear energy. Kosenius and Ollikainen [45] showed for the Finnish case, that energy from plants, which can also be used as food, is the least frequently chosen energy option compared to energy production from wood, wind or water. In a meta-study of the recent literature, Ma et al. [20] described that consumers have a higher WTP for solar and wind energy than for energy from biomass.

The literature reveals that energy from biomass is a component of the green electricity portfolio which is often negatively viewed by consumers $[42,44,45]$. In the German context, energy from biogas in particular is often criticized [16,31], but there is no study that investigates whether consumer rejection of biogas can lead to the decision not to switch to green electricity. Thus, the following hypothesis was derived:

$\mathrm{H} 1$ - The consumer prefers electricity from solar and wind energy over electricity from biogas.

\subsection{Influence of where the participant lives}

As far as the effect of consumer socio-demographics on the WTP for green electricity has been considered, the influence of the region and the town size in which the consumer lives has so far been neglected in German studies. However, it can be assumed that both characteristics have an influence on the WTP, since large price differences for green electricity tariffs within the country can be observed [46, 47]. Furthermore, the town size could stand as a proxy for the degree to which consumers have been exposed to renewable energy, as it is conceivable that consumers in rural areas are more effected e.g. by the strong expansion of biogas production or the increasing installation of wind power plants [29, 30, 31]. However, findings of Liebe et al. [48] and Meyerhoff [49] showed in the context of wind power generation that respondents who already had turbines in their vicinity were more likely to accept new ones than those who have not yet been affected by wind power generation. Hence, the hypotheses were formulated as follows:

$\mathrm{H} 2 \mathrm{a}$ - The participant's WTP for a green electricity tariff is dependent on the region where he or she lives.

$\mathrm{H} 2 \mathrm{~b}$ - The participant's WTP for a green electricity tariff is dependent on the town size in which he or she lives.

\subsection{Influence of a person's attitude towards the EEG levy}

The German Renewable Energy Sources Act guarantees green electricity producers a priority feed-in of their electricity by transmission system operators for a period of 20 years [12]. In accordance with Klaassen et al. [50], it is useful to shift the costs of generating and providing electricity from RES to all consumers in order to ensure the development of climate-protecting innovations and the profitability of the electricity-producing industry in the future. In the case of Germany, transmission system operators carry the costs of marketing green electricity to the customers with the so-called EEG levy [51]. In terms of figures, this means that a typical German household with an average annual electricity consumption of 3,500 kilowatt hours $(\mathrm{kWh})$ paid about $84 €$ per month for electricity in 2016 , of which the EEG levy 
accounts for $22 \%$, or $18 €$ [52]. If consumers have a corresponding WTP, the apportionment model appears appropriate. However, a representative survey conducted by the Renewable Energies Agency (AEE) revealed that $31 \%$ of the participating consumers perceive the EEG levy to be too high [53]. It is conceivable that at least some consumers have this opinion because they generally think that the EEG levy is an unjust instrument to push the expansion of renewable energies. This may lead to consumer backlash and low switching rates [54]. Therefore, the following hypothesis was derived:

\section{H3 - The willingness to switch to a green electricity tariff depends on the acceptance of the EEG levy. 2.4 Environmental awareness and personal lifestyle}

Numerous studies have confirmed that a relationship exists between environmental awareness of consumers and their preference for or the purchase of green electricity $[14,43,45]$. Clark et al. [55] as well as Wiser [56] pointed out that individuals with a greater awareness of their own responsibility in society, knowledge about environmental issues, and a willingness to do something for the environment are more likely to have an interest in electricity from RES. If people acknowledge that climate change exists and that they can contribute to its mitigation through a more environmentally conscious way of life, they often show an increased preference for green electricity [57]. MacPherson and Lange [58] revealed that people with high income, Green Party supporters, and people with very environmentally conscious behavior in their everyday life have more often switched to green electricity tariffs in the past. Kotchen and Moore [59] also noted that specific personal characteristics, such as environmental awareness, have an influence on the adoption of a green electricity tariff. Based on these relationships found by previous studies, the following hypothesis was formulated:

\section{H4 - An environmentally conscious way of life leads to a higher WTP for green electricity. \\ 2.5 Influence of the participant's desire to avoid transaction costs}

Electricity is a low-involvement product, on which the consumer does not want to spend too much time [60]. This is one way to explain why about one third of the German population still obtains their electricity via basic tariffs, which are the most expensive alternative to receive electricity [61]. 40\% of Germans are dissatisfied with the prices of their electricity tariffs [34], but only $6.4 \%$ of private households actively switched their electricity suppliers in 2015 [61]. In this context, comparison portals on the internet serve as the main information source for more than half of the households [34]. The advantage of these portals is that they provide the opportunity to gain comprehensive information in a short time. However, by proceeding in this way, the consumer bears the risk of not being able to find the best provider or tariff for his/her purposes. We therefore derived the following hypothesis:

H5 - The number of tariff switches would increase if consumers could outsource the switching process to someone else.

\section{Methods}




\subsection{The stated preferences approach}

Preference analysis differentiates between revealed and stated preferences. The former aims to observe real market behavior of individuals. Through the verifiable purchase of a product, "real" preferences become visible [62]. With this approach, however, it is not possible to display preferences for hypothetical scenarios and services [62, 63]. Furthermore, in order to examine the preferences of German households for switching to green electricity tariffs and their WTP for certain tariff attributes, utilization of an experimental design within the stated preferences approach is advisable. By doing so in the present study, we avoided the problem of not being able to get a sufficiently detailed dataset of attributes that influence whether a person switches to green electricity [16]. Therefore, the stated preference approach is the method of choice as it allows for drawing conclusions regarding previously un-articulated preferences [62]. According to Louviere et al. [62], this approach recognizes preferences as internalized settings of an individual which can be revealed by means of a survey.

Since sufficient empirical data for an econometric analysis of consumers who are about to switch their tariffs was not available, a discrete choice experiment (DCE) was used, in which an attribute-based measure of respondents' preferences was possible through a scenario of hypothetical decision-making situations [35]. This approach has several advantages over a WTP analysis which directly asks participants for WTP values. Firstly, the decision situation for or against a new tariff is closer to reality, since a DCE enables researchers to confront the participants with so-called "choice sets" containing different alternatives that they can choose from [16]. This organizational setting can be understood as a replication of real-life conditions, in which electricity customers are confronted with a broad variety of different tariffs. Each given alternative in this type of experiment consists of pre-defined attributes and their associated levels. These attributes and their levels are

then systematically varied to determine the respective influence on the selection decision $[16,62]$. Secondly, the closed design in the choice sets is cognitively less demanding than open questions, thereby eliminating the risk of "wild guesses". Finally, compared to an open 
measurement, employing a DCE bears a lower risk of strategic responses, therefore the expressed WTP is more accurate [64].

\subsection{The discrete choice experiment - attributes and levels}

In the DCE, the participants were confronted in several decision situations with the

following hypothetical scenario: "Please imagine that you can switch your electricity tariff today. Your new electricity provider offers you two different tariffs, which both have a contract term of 12 months. The electricity consumption is based on the German average household and amounts in the following tariffs to 3,500 kilowatt hours per year. However, this is not the quantity that needs to be taken. If you opt for one of the two tariffs, your new provider will arrange the termination of the contract with your current supplier, and the switch will be completed". The offered green electricity tariffs varied in the following five attributes: "energy source", "share of green energy", "switching bonus", "price guarantee", and "tariff price". The attributes were selected based on tariff offers of the most popular online switching portals verivox.de and check24.de [65] to enable a realistic experimental design. Furthermore, the results of a literature review, the analysis of current tariff data, and the findings of a pretest all contributed to the design of the contract alternatives as they are shown in Table 1. The attribute-levels were related to an expected annual electricity consumption of 3,500 $\mathrm{kWh}$, the German average household consumption [61] and a contract term of 12 months as this is the standard contract term.

Each decision situation (choice set) provided two different and mutually exclusive tariff alternatives. The tariffs were neutrally referred to as "Tariff A" and "Tariff B", so as not to indicate any differences. Furthermore, the choice sets contained a status-quo alternative ("no switch"), since consumers have the opportunity to keep their current tariffs under reallife conditions as well.

Table 1 - Attributes and levels of the DCE for an expected average electricity consumption of 3,500 kWh year-1 
Green energy source

Share of green energy

Share of green energy

solar, biogas, wind, renewable energy-mix [45\% wind, 25\% biomass

(15\% biogas) , $20 \%$ solar, $10 \%$ hydro power]

$$
40 ; 60 ; 80 ; 100
$$

$\%$ of the

new tariff

$$
1,400 ; 2,100 ; 2,800 ; 3,500
$$

kWh year ${ }^{-1}$

\section{Switching bonus ${ }^{a}$ )}

Price guarantee

Tariff price (incl. switching

bonus and fees) ${ }^{\text {b) }}$
$30 ; 60 ; 90 ; 120$

$0 ; 6 ; 12$

70; 75; 80; 85

770; 825; 880; 935

$22.0 ; 23.5 ; 25.1 ; 26.7$
Euro (€)

Months

Euro

month $^{-1}$

Euro year

Ct kWh ${ }^{-1}$

Source: Author's elaboration

a) The switching bonus refers to a contract term of 12 months. It is a one-time payment that is paid as a discount on the annual tariff price.

b) The tariff price refers to a contract term of 12 months. Bonus payments are already included in the annual tariff price.

\subsection{The experimental design}

The experimental design of the DCE was comprised of two generic alternatives, four attributes with four levels each and one attribute with three levels (cf. Section 3.2), thus resulting in a full-factorial design with $\left[(4 \cdot 4 \cdot 4 \cdot 4 \cdot 3)_{\text {Tariff A }} \cdot(4 \cdot 4 \cdot 4 \cdot 4 \cdot 3)_{\text {Tariff } B}=\right] 589,824$ possible decision situations or choice sets. In this design, all possible main and interaction effects were included [66]. However, for the sake of practicability, this design was determined to be too extensive and therefore, the number of choice sets was reduced. To minimize the simultaneous and unavoidable loss of information when reducing the full factorial design, a so-called "efficient design" was applied. Efficient designs [66, 67, 68] require ex-ante information regarding the population's utility parameters since these designs aim to minimize the standard errors of the utility parameters for the estimation process. This information for the final experiment was obtained by conducting a pretest 
with 30 participants. As a result, a D-efficient Bayesian design [67, 69, 70] was found to be appropriate for our purpose (D-error: 0.051). Thus, the number of choice sets presented to the participants in the final survey was reduced to twelve. As an example, one of the twelve choice sets is depicted in Table 2. A complete list of the choice sets and the experimental setting can be found in Appendix A.

Table 2 - Example of one of the choice sets in the DCE

\begin{tabular}{|c|c|c|c|}
\hline & Tariff A & Tariff B & No Switch \\
\hline Green energy source & Solar & Wind & \\
\hline Share of green energy ${ }^{a)}$ & $\begin{array}{c}80 \% \\
=2,800 \mathrm{kWh}\end{array}$ & $\begin{array}{c}60 \% \\
=2,100 \mathrm{kWh}\end{array}$ & \\
\hline Switching bonus & $30 €$ & $90 €$ & \\
\hline Price guarantee & 6 months & 6 months & \\
\hline Tariff price for $3.500 \mathrm{kWh}$ (incl. switching bonus and fees) & $\begin{array}{c}75 € / \text { month } \\
825 € / \text { year } \\
23.5 \text { Cent/kWh }\end{array}$ & $\begin{array}{c}85 € / \text { month } \\
935 € / \text { year } \\
26.7 \text { Cent/kWh }\end{array}$ & \\
\hline
\end{tabular}

Which alternative do you choose?

Source: Author's elaboration

a) The absolute share of green energy in the tariff is related to an expected average electricity consumption of 3,500 kWh year-1.

\subsection{Data collection}

For the empirical analysis, primary data was collected from residential electricity customers in Germany. An online survey was designed to investigate consumers' preferences for green electricity tariffs and their switching behavior. The final sample was drawn by quota sampling, taking into consideration the distribution of the participants by monthly net income of the household, persons living in one household, and region (north, east, south, and west Germany) since we expected these characteristics to be appropriate for testing the derived hypotheses. The participants were selected by a professional onlinesampling company (respondi) in July and August of 2016. In order to be suitable for the survey and the DCE, the participants had to confirm that they are responsible for their 
household's energy-related decisions. Then, participants who met all necessary criteria to achieve the desired representativeness were recruited. In the survey, participants were firstly asked to provide their electricity consumption data. Next, the DCE was conducted by presenting the choice sets in a randomized order. Then questions were raised to identify differences in the participants' perceptions of green energy sources and their sensitivity towards environmental and climate change issues. The final part of the survey was dedicated to collecting socio-demographic data. A total of 371 participants submitted surveys that could be used for further analysis. Answering the survey took 22 minutes on average.

Excluding the DCE, other data obtained from the survey served as explanatory variables for testing the derived hypotheses. Table 3 gives an overview of which statements from the survey were chosen as additional explanatory variables.

Table 3 - Explanatory variables used in the model estimation for testing the hypotheses 
$\mathrm{H} 1$ - In comparison to other RES, there is no additional WTP for energy from biogas.

H2a/b - The participant's WTP for a green electricity tariff is dependent on the region and the town size in which he or she lives. "food or fuel": Green electricity is only trustworthy if no plants which could alternatively be consumed as food or feed are used for its generation.

"region: east, south, west, north": In which of the following regions do you live?

"town size": How many people live in the place (village, town, city) of your primary residence?
Effect coded:

$1=$

agreement;

$-1=$

disagreement

Effect coded:

1 = east, south, west; $-1=$ north

$1=<5,000$

residents

$2=5,000$ -

19,999

residents

$3=20,000$ -

99,999

residents

$4=100,000$ -

499,999

residents

$5=\geq$

500,000

residents

Effect coded:

"EEG levy acceptance": The EEG levy of costs to all citizens is a good instrument to promote the expansion of renewable energies.
$1=$

agreement;

$-1=$

disagreement
H4 - An environmentally conscious way of life leads to a higher WTP for green electricity.
"Green Party identification": I feel best represented by the political platform of the Green Party.

"environment is important when buying groceries": I consider environmental concerns when I buy my groceries for the week.
Effect coded:

$1=$ agreement; $-1=$ disagreement 
$1=$

agreement;

$-1=$

disagreement

H5 - The number of tariff switches would increase if consumers could outsource the switching process to someone else. "never switched before": Have you ever actively (not moving) switched your electricity tariff?

"wish to outsource switching process": I would be more motivated to switch if there was somebody who could do this for me for a fixed fee of 50 Euros.
Effect coded: $1=$ yes; $-1=$ no

Effect coded:

$1=$ agreement; $-1=$ disagreement

Source: Author's elaboration; translated from German.

\subsection{Model selection}

In order to derive WTP values for the attributes of the DCE with the ultimate goal of giving recommendations for policy-makers and the energy sector, an approach that could produce realistic WTP values was needed. In this context, models in preference space are the current standard method for estimating the WTP of individuals.

A main assumption of these models is that the price coefficient is fixed across individuals. This is necessary because otherwise the WTP is derived by calculating the ratio of two randomly distributed terms, namely the ratio of the distribution of the non-monetary attribute and the distribution of the price coefficient. Unfortunately, this procedure often results in unrealistic and invalid distributions for the WTP [70, 71]. However, handling the price coefficient as a fixed value is an unnecessarily restrictive assumption as it does not to account for heterogeneity in the price coefficient and furthermore, assumes that the scale parameter and therefore, the variance in the error term are identical for all individuals. Consequently, this unidentified scale heterogeneity can be erroneously attributed to a variation in the WTP [63]. 
However, models in WTP space are able to overcome this problem since coefficients of the WTP are directly estimated by re-formulating the model. In this case, assumptions regarding the distributions of the WTP are made directly rather than on the attribute coefficients. Therefore, in these models, it is possible to differentiate preference from scale heterogeneity, and hence to account for differences in the degree of heterogeneity in the DCE. A stated preference approach was used in our study, so this aspect of the method is particularly relevant, since each consumer interpreted and responded to each decision situation differently. By applying a generalized multinomial logit (GMNL) model in WTP space [36], our results were estimated while taking preference and scale heterogeneity into account.

Studies analyzing DCEs with GMNL models in WTP space can be found in a growing number of fields such as food production [38], environmental sciences [72] and agricultural economics $[73,74]$. However, despite the great advantages of this model specification, it had not been used previously for measuring consumer preferences in the field of energy from RES. The general equations underlying the estimation process can be found in Appendix B.

\section{Results And Discussion}

\subsection{Description of the sample}

The sample was drawn by quota sampling, considering participating households' monthly net income, the number of persons living in one household, and region. We expected that region and town size could affect the decision for or against an offered tariff. Therefore, we divided the federal states of Germany into four regions[1] based on the cardinal directions. The variable "town size" was divided into five groups, and ranged from "less than 5,000 residents" to "more than 500,000 residents" following the classifications of the German Federal Statistical Office (see Appendix C).

The participating consumers were between 18 and 78 years old, with a representative average age of 44 [75]. Individuals younger than 18 years old were not included in the survey, since few people younger than 18 live in their own households and make decisions 
regarding their electricity tariffs. In our sample, females were slightly overrepresented compared to the general German population in 2015 (57\% vs. 52\%) [76]. However, since the focus of this investigation was rather on individuals who are responsible for household energy-related decisions, the gender distribution of surveyed decision-makers may differ from the general German population. A total of $24 \%$ of sampled individuals had obtained the general higher education entrance qualification and another $24 \%$ held a university degree as the highest qualification level.

Considering the electricity consumption data, participants used 2,750 kWh per year on average and paid about $750 €$ for their annual electricity bill. The latter value is considerably lower than the German average annual electricity bill, which amounted to $1,008 €$ in 2016 [52]. This difference may be due to the assumption that an average household has an electricity consumption of 3,500 kWh per year, while in our sample, $69 \%$ of the respondents stated that they consume less. Furthermore, only $6.4 \%$ of all German households switched their energy provider in 2015, meaning that few people have benefited from a cost reduction in their electricity bill [61], whereas in our sample, a quarter of the individuals switched their provider or tariff within the past year.

Statements relevant to the hypotheses showed the following response frequencies: half of the sampled individuals stated that green electricity is only trustworthy if no plants which could alternatively be consumed as food or feed are used for its generation. A quarter of the participants agreed that the EEG levy is a good instrument to promote the expansion of renewable energies. However, 63\% agreed that the demand for green energy could be increased through the elimination of the EEG levy for those who decide to receive pure green energy. $12 \%$ of the participants felt well-represented by the political platform of the Green Party, which are slightly more than in the general election in 2017 [77]. 52\% of individuals considered environmental concerns when they buy their groceries. Although two thirds of participants had a positive attitude towards green energy, $31 \%$ of the participants had never taken the initiative to switch. About $16 \%$ of the participants would be more motivated to switch if there was somebody who could do this for them for a fixed fee of 50 Euros. Full descriptive statistics are provided in Appendix C. 


\subsection{General findings of the GMNL model in WTP space}

Table 4 presents a basic model (Model 1) which represents the WTP of the average consumer as well as a model that includes several participant-specific variables as interaction terms with different tariff attributes (Model 2). Both were estimated in WTP space as a specified form of the GMNL model $[36,37]$ by implementing the Stata module of $\mathrm{Gu}$ et al. [78] using 1,000 Halton draws. These interaction terms account for possible causes of the observed heterogeneity in the valuation of the random parameters "alternative-specific constant (ASC)", "share of green energy", "switching bonus", and "price guarantee" which are characterized by the standard deviations of the random parameter distributions of Model 1. As suggested by Hensher et al. [79], interactions that were not significant were excluded from the estimation process as they could have had an effect on the other coefficients within the model. Therefore, other tested variables, such as the participants' educational level or the size of the household, were not considered in the final model estimation since they lacked significance. In order to prove the explanatory power of the models, the pseudo- $\mathrm{R}^{2}$ was used as a goodness-of-fit measure. The values show that Model 2, with a pseudo- $\mathrm{R}^{2}$ of 0.32 , is an improvement of Model 1 . According to Hensher et al. [79], a pseudo- $\mathrm{R}^{2}$ of at least 0.3 represents an appropriate model fit. The underlying STATA-code can be found in Appendix D.

Table 4 - Generalized multinomial logit model in willingness-to-pay space ${ }^{\text {a) }}$ 


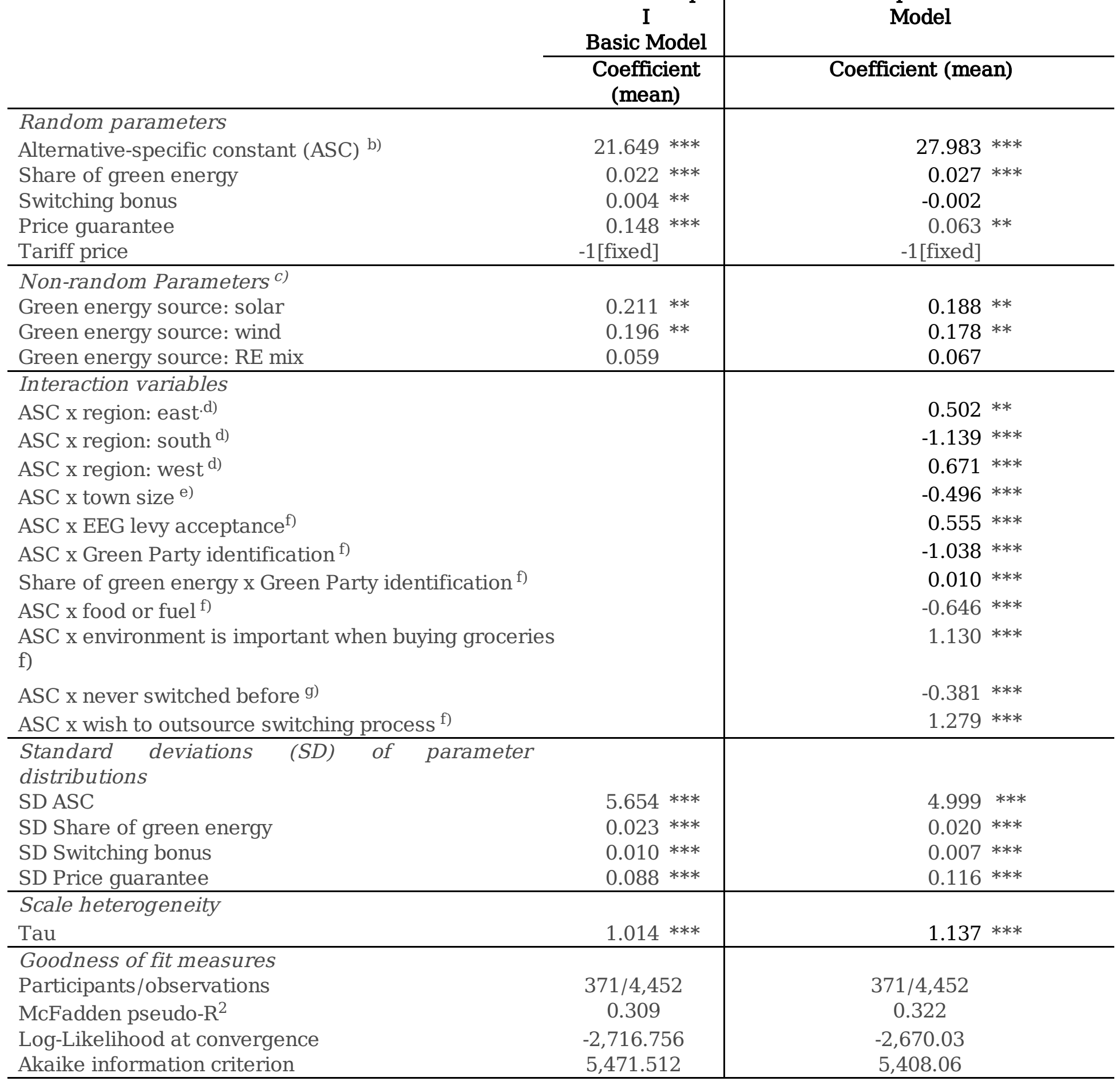

Source: Author's calculations by means of the STATA-command "gmnl" in STATA 14 using 1,000 Halton draws.

Notes: a) $* \mathrm{p}<0.1$; ** $\mathrm{p}<0.05$; *** $\mathrm{p}<0.001$; randomized WTP coefficients with significant SD are assumed to be normally distributed and correlated; the price coefficient was normalized to be log-normal and constrained to $-1$.
b) Binary coded variable; reference: status-quo alternative "No switch."
C) Effect coded; reference: "Energy source: biogas".
d) Effect coded; reference: "Region: north". 
e) The variable "town size" was divided into five groups, and ranged from "less than 5,000 residents" to "more than 500,000 residents". For a detailed structuring of the groups see Appendix C.

f) Effect coded; reference: "Participant does not support the queried statement".

g) Effect coded; reference: "Participant switched the electricity tariff at least once before".

The price coefficient was normalized to -1 , and the other coefficients represent the WTP for each variable. The models include a dummy-coded ASC, which was valued at one for choosing one of the tariff alternatives and zero for the status-quo alternative "no switch". The significant ASC of Model 1 implies that the average participant is willing to pay 21.6 Eurocent $\mathrm{kWh}^{-1}$ for an offered green electricity tariff instead of choosing no offered tariff (status-quo alternative). This value reflects a general WTP for green electricity as all offered tariffs within the DCE contained green electricity. On average, German consumers paid about 28.8 Eurocent $\mathrm{kWh}^{-1}$ for their electricity in 2016 [52], indicating that a tariff switch can be strongly motivated by a price reduction. However, this relatively high value arises from the fact that about one third of the consumers received electricity via basic tariffs, which are the most expensive way to obtain electricity [61]. Considering all available existing pure green energy tariffs in Germany, the average cost for one kilowatt hour was only 22 Eurocent $\mathrm{kWh}^{-1}$ in 2016 [46]. Therefore, it can be assumed that the estimated WTP of 21.6 Eurocent $\mathrm{kWh}^{-1}$ for switching to a green electricity tariff reflects a realistic amount.

The attribute "share of green energy" was measured in percent and described the proportion of green energy sources in the tariff for an annual electricity consumption of 3,500 kWh. Model 1 shows that on average, the WTP increased by 0.022 Eurocent $\mathrm{kWh}^{-1}$ if the share of green energy increased by 1\%. For instance, the lowest offered green energy share in the tariffs was $40 \%$, resulting in an additional WTP of 0.88 Eurocent $\mathrm{kWh}^{-1}$ $(0.022 * 40)$, meaning that participants would agree to pay 2.4 Eurocent $\mathrm{kWh}^{-1}$ more for a pure green energy tariff if they decided to switch their tariff. In terms of the annual 
electricity bill, this means a sum of $77 €(0.022 * 100 * 3,500)$. The influence of the "switching bonus" was also significant if the participants were willing to opt for a new tariff. Model 1 reveals that for a one Euro increase in the bonus payment, participants would pay 0.004 Eurocent $\mathrm{kWh}^{-1}$. Thus, in order to receive the maximum offered switching bonus of $120 €$, the average participant was willing to spend $16.8 €(0.004 * 120 * 3,500)$ more on the annual electricity bill. The "price guarantee" was given in months and led to a relatively high WTP, as shown in Model 1. If the average participant decided to switch his/her tariff, he/she was willing to pay 0.15 Eurocent $\mathrm{kWh}^{-1}$ for every additional month the guarantee is extended. In other words, regarding an annual electricity consumption of 3,500 kWh, a 12-month guarantee was valued by the average participant at $63 €$. The variable "energy source" was effect coded, meaning that "biogas" acted as a reference for the other energy sources. The coefficient for biogas was then calculated as suggested by Hensher et al. [79] using the following equation: $\mathrm{WTP}_{\text {biogas }}=-\left(\mathrm{WTP}_{\text {solar }}+\mathrm{WTP}_{\text {wind }}\right)$. Thus, the coefficient was -0.407 $(-0.407=-(0.211+0.196))$, as it can be understood from Model 1. This suggests that participants had a WTP for a tariff including solar or wind energy but not for a tariff with biogas energy. Furthermore, no significant WTP for a renewable electricity mix was found.

\subsection{Hypotheses testing}

\section{Hypothesis 1 - Different preferences regarding RES}

The results of Model 1 reflecting the average consumer's preferences were used for testing Hypothesis 1 since no preference heterogeneity was determined for the coefficients of the energy sources "solar", "wind", and "RE mix". The green energy source "biogas" acted as a reference for the other energy sources. The results revealed that consumers have a marginally higher WTP for solar energy than wind energy (coefficients: 0.211 vs. 0.196) if "biogas" is understood as the reference. Furthermore, a renewable electricity mix does not motivate participants to pay more than for biogas in a potential new tariff, as the coefficient was not significant. This indicates that if consumers have the choice between the energy sources presented in this study, neither biogas nor a RE mix are energy sources that 
facilitate an increased rate of tariff switching. This is contrary to Burkhalter et al. [32], who reported that a green electricity mix is more appreciated by consumers than green electricity from a single source. However, if consumers have a negative perception of biogas production and more specifically, of RES that can alternatively serve as feed or food $[42,45]$, it seems plausible that a green electricity mix containing energy of this origin is more likely to be rejected. This assumption was confirmed by the negative coefficient of the interaction term "ASC $\mathrm{x}$ food or fuel" (Model 2: -0.646). Without accounting for specific tariff arrangements, it was shown that if a participant does not want to support an energy source that can either serve as food or fuel, his/her WTP decreases by 0.646 Eurocent kWh

1. Consequently, our results corroborate other scientific studies that also found that if consumers consider switching to green energy tariffs, they have a general WTP for green electricity products, but that this varies over different energy sources [16, 20, 41-45]. In light of these results, H1: the consumer prefers electricity from solar and wind over electricity from biogas can be confirmed.

\section{Hypotheses $2 a / b$ - Influence of where the participant lives}

The northern states of Germany served as the reference for the estimations in Model 2, since consumers pay an average value for green electricity compared to the other regions [46]. Our results showed that compared to the north, the south has the significantly lowest WTP for switching to green electricity (ASC x region: south: -1.139 Eurocent $\mathrm{kWh}^{-1}$ ), whereas households in the east or west would pay significantly more than households in the north for switching to green electricity (ASC x region: east: 0.502 Eurocent $\mathrm{kWh}^{-1}$, ASC $\mathrm{x}$ region: west: 0.671 Eurocent $\mathrm{kWh}^{-1}$ ). One possibility to explain these regional differences is to take into account the different network charges that consumers have to pay depending on the network operator. In general, it can be stated that households in the east pay significantly more for their electricity than households in the west $[46,47,80]$. This results from higher costs for the network expansion in the east, since here lots of renewable energy is produced which needs then to be fed in the grid and distributed. However, we did 
not find that households in the east want a discount compared to the reference households in the north. Therefore, another path to explain our findings could be that even if different WTP values for switching to green energy are found in different regions, these values are not different because of the region and the average electricity price in each region. The household size, the income situation, as well as the tariff availability depending on where a participant lives, could have influenced the participants' WTP in the observed regions.

The coefficient "ASC $\mathrm{x}$ town size" was significantly negative (-0.496). The coefficient can be interpreted as follows: the bigger the town a person lives in, the lower the WTP for a green electricity tariff switch. In other words, participants who live in very large cities with more than 500,000 residents have five times lower WTP (-2.48 Eurocent $\mathrm{kWh}^{-1}$ ). In terms of the annual electricity bill, this means that these participants want to pay about $86.8 €$ less (5* $(-0.496) * 3,500)$. This is an interesting finding, as on the one hand, it is conceivable that people who live in rural areas (represented by the smallest town unit) are more impacted by negative effects of renewable energy production, and therefore it could be expected that these participants would have the lowest WTP. On the other hand, and this is what our results suggest, it can be assumed that these participants are probably closer to nature and more involved in renewable energy production, and therefore have the highest WTP. This is in line with findings of Liebe et al. [48] and Meyerhoff [49] who showed in the context of wind power generation that respondents who lived further away from turbines were more likely to be opponent to wind power generation, whereas respondents who already had turbines in their vicinity were more likely to accept new ones. However, since this is probably the first study that considered the influence of where a person lives on whether a person wants to switch to green energy or not, further studies could analyze why consumers in towns want to pay less. Nevertheless, it becomes evident that H2: the participant's WTP for a green electricity tariff is dependent on the region and the town size cannot be rejected.

Hypothesis 3 - Influence of a person's attitude towards the EEG levy 
The survey included the question of whether the participants perceived the EEG levy of costs to all citizens as a good instrument to promote the expansion of renewable energies. About $26 \%$ of the sample agreed with this. For those who supported this statement, the WTP increased significantly (by 0.56 Eurocent $\mathrm{kWh}^{-1}$ ) if they decide to switch their tariff ("ASC x EEG levy: likely instrument"). However, the WTP decreased by the same amount for individuals who disagreed with this statement. In terms of the annual electricity bill, this amounts to $19.6 €$ that participants were (not) willing to pay more. Since the EEG levy, in reality, costs consumers $216 €$ per year at a consumption level of 3,500 kWh [52], our findings indicate that the WTP of participants who agreed (disagreed) with the EEG levy was $236 €(196 €)$. Thus, H3: the willingness to switch to a green electricity tariff depends on the acceptance of the EEG levy cannot be rejected, even if the influence of a person's attitude is rather modest in terms of concrete figures. However, to explain why the majority of the participants want to reach a tariff price discount by reducing the amount of the EEG, it may be helpful to know that currently only $42 \%$ of the EEG levy is used to promote the expansion of renewable energies [81]. If participants have knowledge of this, it is conceivable that they consider the EEG levy to be an inappropriate mechanism. This assumption was additionally supported by $63 \%$ of participants, who stated in the survey that the demand for green energy could be increased through the elimination of the EEG levy for those who decide to receive pure green energy. For policy makers, this could be an interesting approach to motivate consumers to buy pure green energy. Consumers who decide to opt for a pure green energy tariff could be rewarded with a discount in the amount of the EEG levy, whereas all other groups of electricity customers who do not support the energy transition by purchasing green energy might be charged a penalty.

\section{Hypothesis 4 - Environmental awareness and personal lifestyle}

It seems obvious that people with a high awareness regarding environmental and sustainability issues are more likely to be interested in buying green electricity [53, 56, 57]. One way to gain information about consumer awareness is to ask whether participants are Green Party supporters [58]. In this study, the question was raised whether participants 
feel represented by the political platform of the Green Party. Those who identified with the Green Party showed a significantly reduced WTP for a switch to the offered green energy tariffs ("ASC x Green Party identification" = -1.038). This might be due to the fact that from the viewpoint of Green Party supporters, the offered tariffs could have included unfavorable energy sources, such as biogas. Interestingly, it was evident that the same participants had a rising WTP for each percentage increase in the share of green energy in the offered tariff ("share of green energy x Green Party identification" = 0.010). Therefore, it is conceivable that participants who felt represented by the Green Party considered switching to a green energy tariff only if this tariff consisted of pure green energy sources. If this is true, other tariffs that comprise lower shares of green energy, including the electricity-mix currently offered in Germany, might not be a successful way to encourage this consumer group to switch to "greener" energy tariffs.

The influence of awareness of environmental issues on the participants' decision to switch tariffs was also shown by the significant coefficient of the interaction term "ASC $\mathrm{x}$ environment is important when buying groceries" $=1.130$. This result indicates that consumers who consider environmental issues in their daily life, e.g. when doing the weekly grocery shopping, have a higher WTP for switching to a green energy tariff. It is also conceivable that consumers who aspire to lead an environmentally-friendly lifestyle are more likely to switch their energy tariff to a green energy tariff since this kind of energy contributes to their desired way of life. Consequently, H4: an environmentally consciousness way of life leads to a higher WTP for green electricity cannot be rejected.

Hypothesis 5 - Influence of the participant's desire to avoid transaction costs

There are several reasons, why consumers do not switch their electricity tariffs, even if switching would lead to financial benefit $[24,25,26]$. It was revealed that if a participant had never switched his/her tariff, then he/she had a significantly lower WTP regarding a switch to a green energy tariff ("ASC $\mathrm{x}$ never switched before" $=-0.381$ ). This result can be understood as a confirmation that certain obstacles to consumers switching their tariff exist. Thus, participants were asked in the survey whether they were more motivated to switch if they could outsource the switching process to someone else. The significant 
coefficient of the interaction term "ASC $\mathrm{x}$ wish to outsource the switching process" $=1.279$ shows that participants who want to outsource the switching process demonstrate their appreciation of this assistance with an increased WTP. In light of these results, H5: the number of tariff switches would increase if consumers could outsource the switching process to someone else is supported and cannot be rejected. Therefore, offering a "fullservice switch" could be one way to increase green energy adoption rates.

[1] The distribution of the federal states to the regions was as follows: north (Bremen, Hamburg, Lower Saxony, Schleswig-Holstein), east (Brandenburg, Mecklenburg-Western Pomerania, Saxony, SaxonyAnhalt, Thuringia, Berlin), west (North-Rhine Westphalia, Saarland), south (Bavaria, Baden-Wuerttemberg, Hesse, Rhineland-Palatinate).

\section{Conclusions}

This paper presents the results of a quota-representative discrete choice experiment with 371 German electricity consumers conducted to elicit factors that are important for consumers when deciding whether to switch to green electricity. In order to provide policy makers and marketers with a valuable understanding of consumer behavior with regard to demand for green energy electricity, an estimation approach was chosen that produces WTP values that are as realistic as possible. Therefore, this study allows policy makers and electricity marketers to gain insights into how specific parameters influence consumers' WTP, which might be worth considering in order to increase adoption rates of green energy electricity in private households. This is particularly important since Germany aims to rely solely on renewable energy sources in the future [82].

Considering the gap between consumers' intentions and consumers' actions, the following implications can be drawn from the results of this tariff switching experiment: In order to make switching to green energy tariffs more attractive for consumers, electricity marketers and policy makers should focus on support of pure green energy tariffs that solely consist of solar or wind energy. As our findings indicate, in the context of energy tariffs from renewable energy sources, German consumers are reluctant to switch to a green energy tariff if the source of green energy is biogas or a mix of different renewable energies that also contains biogas as a source. This is supported by the result that if plants which can also serve as food or livestock feed are used to produce green electricity, the WTP decreases for a green energy tariff. Therefore, the support of solar and wind energy should be a priority for politicians as these energy sources are specifically demanded by the consumer. In addition, marketers could demand higher prices if they can offer such differentiated tariffs.

A further implication is that marketers should replace the "general" switching bonus with a specifically "framed" bonus in the amount of the current EEG levy. As suggested by our results, the EEG levy is a 
reason why consumers have lower WTP for a switch to a green tariff. Therefore, a "framed bonus" could be a promising way to increase adoption rates of green energy tariffs, especially for those who are critical of the EEG levy. Furthermore, policy makers could take this point as a suggestion to consider whether a reward and punishment policy could be more promising than the current EEG levy to promote renewable energy expansion.

We also suggest that attention should be given to psychological and behavioral aspects, as they are of great influence on consumers in their decision whether to switch to green energy. This is in line with Tabi et al. [57], who also suggested that these aspects should be considered "when it comes to understanding why consumers who evince strong preferences towards electricity produced from renewable energy sources do not act according to their preferences by opting to purchase green power". We found, for example, that if marketers offered a "full-service switch" or a "subscription for frequent switches", this could be a great opportunity to increase green tariff adoption rates for consumers who try to avoid transaction costs. However, there may also be other factors that play a role when consumers consider outsourcing the switch. Therefore, further research could investigate which authorities consumers consider to be trustworthy enough to carry out the switch for them.

These conclusions are based on the results of a DCE. Although we designed the experiment as realistically as possible and used an analytical approach that enables estimation of actionable WTP values, this piece of research suffers from the same limitations as any other study, and may therefore serve as starting point for further research. For instance, findings regarding the region and town size suggest more investigation is necessary in order to determine the influence of these characteristics on the consumers' WTP for green energy. Therefore, the population of rural areas and their exposure to RES production should be investigated more in detail. Additionally, as our results relate to a fixed annual electricity consumption of 3,500 kWh, reflecting the average German household [52], it could be interesting to design a DCE that relies on the real consumption data of the participating individuals. Such an adjustment could be helpful to reduce the potential hypothetical bias that may lead to overestimation of the WTP in choice experiments [20, 83]. Furthermore, this study is limited to Germany, so it would be enlightening if further research could apply our experimental design to investigate whether consumers of other countries have similar preferences.

\section{Abbreviations}

AEE: Renewable Energy Agencies; ASC: Alternative specific constant; DCE: Discrete choice experiment; EEG: Renewable Energy Sources Act; EU: European Union; GMNL: Generalized Multinomial Logit; kWh: Kilowatt hours; RES: Renewable energy sources; SD: Standard deviation; WTP: Willingness to pay.

\section{Declarations}

\section{Ethics approval and consent to participate}


Not applicable.

\section{Consent for publication}

Not applicable.

\section{Availability of data and materials}

The datasets used and/or analyzed during the current study are available from the corresponding author on reasonable request.

\section{Competing interests}

The authors declare that they have no competing interests.

\section{Funding}

Not applicable.

\section{Authors' contributions}

MD, SS and OM contributed to the design of the work. MD and SS are responsible for acquisition of data (in Germany), drafting of the work, and management work. MD has analyzed the data. The authors read and approved the final manuscript.

\section{Acknowledgements}

Not applicable.

\section{References}

1. Haas R, Panzer C, Resch G, Ragwitz M, Reece G, Held A (2011) A historical review of promotion strategies for electricity from renewable energy sources in EU countries. Renew Sust Energ Rev 15(2):1003-1034

2. IEA (International Energy Agency) (2015) IEA Statistics. Key Renewable Trends. Excerpt from: Renewables Information. . Accessed: 25 Jan 2016

3. IEA (International Energy Agency) (2016) World Energy Outlook. . Accessed: 17 Apr 2017

4. Eurostat (2016) Greenhouse gas emission statistics. . Accessed 16 Feb 2017

5. Oberthür S, Kelly CR (2008) EU Leadership in international climate policy: Achievements and challenges. Int Spect 43(3):35-50

6. Parker CF, Karlsson C (2010) Climate change and the European Union's leadership moment: An inconvenient truth? J Common Mark Stud 48(4):923-943 
7. Eurostat (2017) Renewable energy in the EU. Share of renewables in energy consumption in the EU still on the rise to almost 17\% in 2015. . Accessed 03 Apr 2017

8. BMUB (Federal Ministry for the Environment

Building and Nuclear Safety)

BMUB (Federal Ministry for the Environment, Conservation N, Building and Nuclear Safety) (2014) The German Government's Climate Action Programme 2020. . Accessed 15 Jul 2016

9. UBA (Federal Environment Agency) (2016) National Inventory Report, Germany - 2016. . Accessed 18 Jul 2016

10. EEG (Renewable Energy Sources Act - RES Act) (2000). Accessed 20 Apr 2015

11. BMWi (Federal Ministry for Economic Affairs and Energy) (2015) The Energy of the Future. property=pdf,bereich=bmwi2012,sprache=en,rwb=true.pdf. Accessed 29 Jan 2016

12. EEG (Renewable Energy Sources Act - RES Act) (2014) -2014,property=pdf,bereich=bmwi2012,sprache=en,rwb=true.pdf. Accessed 20 Apr 2015

13. Aravena C, Hutchinson WG, Longo A (2012) Environmental pricing of externalities from different sources of electricity generation in Chile. Energy Econ 34(4):1214-1225

14. Gerpott TJ, Mahmudova I (2010) Determinants of green electricity adoption among residential customers in Germany. Int J Consum Stud 34(4):464-473

15. Hansla A (2011) Value orientation and framing as determinants of stated willingness to pay for ecolabeled electricity. Energ Effic 4(2):185-192

16. Kaenzig J, Heinzle SL, Wüstenhagen R (2013) Whatever the customer wants, the customer gets? Exploring the gap between consumer preference and default electricity products in Germany. Energ Policy 53:311-322

17. Litvine D, Wüstenhagen R (2011) Helping "light green" consumers walk the talk: results of a behavioral intervention survey in the Swiss electricity market. Ecol Econ 70(3):462-474

18. Longo A, Markandya A, Petrucci M (2008) The internalization of externalities in the production of electricity: Willingness to pay for the attributes of a policy for renewable energy. Ecol Econ 67(1):140-152

19. Oliver H, Volschenk J, Smit E (2011) Residential consumers in the Cape Peninsula's willingness to pay for premium priced green electricity. Energ Policy 39(2):544-550

20. Ma C, Rogers AA, Kragt ME, Zhang F, Polyakov M, Gibson F, Chalak M, Pandit R, Tapsuwan S (2015) Consumers' willingness to pay for renewable Energy: A meta-regression analysis. Resour Energy Econ 42:93-109

21. Sundt S, Rehdanz K (2014) Consumer's willingness to pay for green electricity: A meta-analysis of the literature. Kiel Working Paper, No.1931

22. Batley SL, Colbourne D, Fleming PD, Urwin P (2001) Citizen versus consumer: challenges in the UK green power market. Energ Policy 29(6):479-487 
23. Salmela S, Varho V (2006) Consumers in the green electricity market in Finland. Energ Policy 34(18):3669-3683

24. Gamble A, Juliusson EA, Gärling T (2009) Consumer attitudes towards switching supplier in three deregulated markets. J Socio-Econ 38(5):814-819

25. Sunderer G (2006) Was hält Verbraucher vom Wechsel zu Ökostrom ab? Schriftenreihe des Zentrums für europäische Studien, Universität Trier. ISSN 0948-1141

26. Yang Y (2014) Understanding household switching behavior in the retail electricity market. Energ Policy 69:406-414

27. BMUB (Federal Ministry for the Environment

Building and Nuclear Safety)

BMUB (Federal Ministry for the Environment, Conservation N, Building and Nuclear Safety) (2016)

Developments in Germany following the nuclear disaster in Japan. . Accessed 24 Nov 2016

28. Herrmann A (2013) Biogas production from maize: current state, challenges and prospects. 2.

Agronomic and Environmental Aspects. Bioenerg Res 6(1):372-387

29. Kintisch E (2010) Out of site. Science 329(5993):788-798

30. Wüstenhagen R, Wolsink M, Bürer MJ (2007) Social acceptance of renewable energy innovation: an introduction to the concept. Energ Policy 35(5):2683-2691

31. Zschache U, von Cramon-Taubadel S, Theuvsen L (2010) Öffentliche Deutungen im Bioenergiediskurs: eine qualitative Medienanalyse. Ber Ldw 88(3):502-512

32. Burkhalter A, Kaenzig J, Wüstenhagen R (2009) Kundenpräferenzen für leistungsrelevante Attribute von Stromprodukten. ZfE, Zeitschrift für Energiewirtschaft 2: 161-172

33. Groesche P, Schroeder $C$ (2011) Eliciting public support for greening the electricity mix using random parameter techniques. Energ Econ 33(2):363-370

34. PWC (Pricewaterhouse Coopers) (2015) Bevölkerungsbefragung Stromanbieter. . Accessed 23 Feb 2017

35. List JA, Sinha P, Taylor MH (2006) Using choice experiments to value non-market goods and services: evidence from field experiments. Advances in Economic Analysis and Policy 6, Art. 2

36. Fiebig DG, Keane MP, Louviere JJ, Wasi N (2010) The generalized multinomial logit model: Accounting for scale and coefficient heterogeneity. Market Sci 29(3):393-421

37. Greene WH, Hensher DA (2010) Does scale heterogeneity across individuals matter? An empirical assessment of alternative logit models. Transp 37(3):413-428

38. Balogh P, Békési D, Gorton M, Popp J, Lengyel P (2016) Consumer willingness to pay for traditional food products. Food Pol 61:176-184

39. Balcombe K, Chalak A, Fraser I (2009) Model selection for the mixed logit with Bayesian estimation. J Environ Econ Manag 57(2):226-237

40. Balcombe K, Fraser I, Falco SD (2010) Traffic lights and food choice: a choice experiment examining the relationship between nutritional food labels and price. Food Pol 35(3):211-220 
41. Borchers AM, Duke JM, Parsons GR (2007) Does willingness to pay differ by source? Energ Policy 35(6):3327-3334

42. Cicia G, Cembale L, Del Giudice T, Palladino A (2012) Fossil energy versus nuclear, wind, solar, and agricultural biomass: Insights from an Italian national survey. Energ Policy 42:59-66

43. Ek K (2005) Public and private attitudes towards "green" electricity: the case of Swedish wind power. Energ Policy 33(13):1677-1689

44. Gracia A, Barreiro-Hurlé J, Peréz y Peréz L (2012) Can renewable energy be financed with higher electricity prices? Evidence from a Spanish region. Energ Policy 50:784-794

45. Kosenius AK, Ollikainen M (2013) Valuation of environmental and societal trade-offs of renewable energy sources. Energ Policy 62:1148-1156

46. Heidjann J (2017a) Regional unterschiedliche Strompreise in Deutschland. . Accessed 17 Apr 2017

47. Strom-Report (2017a) Wo ist Ökostrom am günstigsten? https://1-. Accessed 17 Feb 2017

48. Liebe U, Bartczak A, Meyerhoff J (2017) A turbine is not only a turbine: The role of social context and fairness characteristics for the local acceptance of wind power. Energ Policy 107:300-308

49. Meyerhoff $J$ (2013) Do turbines in the vicinity of respondents' residences influence choices among programmes for future wind power generation? J Choice Model 7:58-71

50. Klaassen G, Miketa A, Larsen K, Sundqvist T (2005) The impact of R\&D on innovation for wind energy in Denmark, Germany and the United Kingdom. Ecol Econ 54(2-3):227-240

51. Kramer R (2015) Gesetzliche Rahmenbedingungen und ihre Auswirkungen auf die Vermarktung von Erneuerbaren Energien in Deutschland. In: Herbes C, Friege C (eds) Marketing Erneuerbarer Energien. Springer Fachmedien, Wiesbaden, pp 61-80

52. BDEW (Federal Association of the German Energy and Water Industries) (2017) BDEWStrompreisanalyse Februar 2017. D9BC12580C8004CC2B8/file. Accessed 14 Mar 2017

53. AEE (Renewable Energies Agency) (2015) Renews Kompakt. . Accessed 26 Jan 2017

54. Dickenberger D, Gniech G, Grabitz HJ (1993) Die Theorie der psychologischen Reaktanz. In Frey D, Irle M (Eds.) Theorien der Sozialpsychologie, Band 1: Kognitive Theorien: 243-276. Bern, Huber

55. Clark CF, Kotchen MJ, Moore MR (2003) Internal and external influences on pro-environmental behavior: participation in a green electricity program. J Environ Psychol 23(3):237-246

56. Wiser RH (2007) Using contingent valuation to explore willingness to pay for renewable energy: A comparison of collective and voluntary payment vehicles. Ecol Econ 62(3):419-432

57. Tabi A, Hille SL, Wüstenhagen R (2014) What makes people seal the green power deal? - Customer segmentation based on choice experiment in Germany. Ecol Econ 107:206-215

58. MacPherson R, Lange I (2013) Determinants of green electricity tariff uptake in the UK. Energ Policy 62:920-933

59. Kotchen MJ, Moore MR (2007) Private provision of environmental public goods: household participation in green-electricity programs. J Environ Econ Manage 53(1):1-16 
60. Friege $C$, Herbes $C$ (2015) Konzeptionelle Überlegungen zur Vermarktung von Erneuerbaren Energien. In: Herbes C, Friege C (eds) Marketing Erneuerbarer Energien. Springer Fachmedien, Wiesbaden, pp 3-28

61. Federal Network Agency (2016) Monitoringbericht 2016. .pdf?_blob=publicationFile\&v=2. Accessed 29 Dec 2016

62. Louviere JJ, Hensher DA, Swait JD (2000) Stated choice methods: analysis and applications, 1 st edn. University Press, Cambridge

63. Train KE (2009) Discrete choice methods with simulation, 2nd edn. University Press, Cambridge

64. Hanley N, Ryan M, Wright R (2003) Estimating the monetary value of health care: lessons from environmental economics. Health Econ 12(1):3-16

65. Heidjann J (2017b) Stromtarife. . Accessed 30 Jan 2017

66. Rose JM, Bliemer MCJ (2009) Constructing efficient stated choice experimental design. Transp Rev 29(5):587-617

67. Bliemer MCJ, Rose JM, Hess S (2008) Approximation of Bayesian efficiency in experimental choice designs. J Choice Model 1(1):98-127

68. Ferrini S, Scarpa R (2007) Designs with a priori information for nonmarket valuation with choice experiments: A Monte Carlo study. J Environ Econ Manage 53(3):342-363

69. Sandor Z, Wedel M (2005) Heterogeneous conjoint choice designs. J Market Res 42(2):210-218

70. Scarpa R, Rose JM (2008) Design efficiency for non-market valuation with choice modelling: how to measure it, what to report and why. Australian J Agric Resour Econ 52(3):253-282

71. Hensher DA, Greene WH (2011) Valuation of travel time savings in WTP and preference space in the presence of taste and scale heterogeneity. J Transp Econ Pol 45(3):505-525

72. Li X, Clark CD, Jensen KL, Yen ST (2014) Will consumers follow climate leaders? The effect of manufacturer participation in a voluntary environmental program on consumer preferences. Environ Econ Pol Stud 16(1):69-87

73. Coffie RO, Burton MP, Gibson FL, Hailu A (2016) Choice of Rice Production Practices in Ghana: A Comparison of Willingness to Pay and Preference Space Estimates. J Agric Econ 67(3):799-819

74. Sauthoff S, Musshoff O, Danne M, Anastassiadis F (2016) Sugar beet as a biogas substrate? A discrete choice experiment for the design of substrate supply contracts for German farmers. Biomass Bioenergy 90:163-172

75. BiB (German Federal Institute for Population Research) (2017) Mean age of the population in Germany. . Accessed 11 May 2017

76. Destatis (German Federal Statistical Office) (2016) Statistisches Jahrbuch 2016. Wiesbaden

77. Federal Returning Officer (2017) Bundestag election 2017. . Accessed 29 Apr 2018

78. Gu Y, Hole AR, Knox S (2013) Fitting the generalized multinomial logit model in Stata. Stata J 13:382-397 
79. Hensher DA, Rose JM, Greene WH (2005) Applied choice analysis: a primer. University Press, Cambridge

80. Strom-Report (2018) Netzentgelte. . Accessed 25 Apr 2018

81. Strom-Report (2017b) Zusammensetzung der EEG-Umlage und Entwicklung der Einflussfaktoren. . Accessed 7 Feb 2017

82. UBA (Federal Environment Agency) (2010) Energy target 2050: 100\% renewable electricity supply. Dessau-Roßlau, Germany

83. Byrnes B, Jones C, Goodman S (1999) Contingent valuation and real economic commitment: evidence from electric utility green pricing programmes. J Environ Plan Manage 42(2):149-166

84. McFadden D (1974) Conditional logit analysis of qualitative behaviour. In: Zarembka P (ed) Frontiers in econometrics. Academic Press, New York, pp 105-142

\section{Supplementary Files}

This is a list of supplementary files associated with this preprint. Click to download.

- Appendix.docx 